Progress in Flight Physics 5 (2013) 583-600

DOI: $10.1051 /$ eucass/201305583

(C) Owned by the authors, published by EDP Sciences, 2013

\title{
EXPERIMENTAL RESEARCH OF THE BOUNDARY LAYER STRUCTURE AT NEAR-CRITICAL ANGLES OF ATTACK FOR THE CLASSICAL AND WAVY WINGS
}

\author{
I. Zverkov, V. Kozlov, and A. Kryukov \\ Khristianovich Institute of Theoretical and Applied Mechanics \\ Siberian Branch of the Russian Academy of Sciences \\ 4/1 Institutskaya Str., Novosibirsk, Russia
}

\begin{abstract}
The structure of the boundary layer on the classical and wavy wings at near-critical angles of attack at the Reynolds number $\operatorname{Re}=140,000$ is studied with the use of oil-film and infrared (IR) visualization. A boundary layer with a specific structure is demonstrated to form on the wing with the wavy surface. This boundary layer is more stable to separation from the wing surface. As a result, the wing with a wavy surface has a greater critical angle of attack and a greater maximum lift coefficient. Improvement of aerodynamic characteristics of the wavy wing, as compared with the classical wing, is confirmed by balance measurements.
\end{abstract}

\section{INTRODUCTION}

Researchers are now again interested in problems associated with the flow around wings of flying vehicles at Reynolds number based on the wing chord below 500,000 . The reason is more extensive applications of unmanned vehicles in civil and military aeronautics. These problems include, for instance, long-time patrolling and airborne prospecting of buildup territories or under conditions potentially hazardous for the crew of manner vehicles. Unmanned vehicles allow using a smaller takeoff weight of the flying vehicle with the same functional load. Reduction of the takeoff weight, however, decreases the Reynolds number based on the wing chord [1], which often becomes lower than 500,000. The aerodynamic characteristics of the vehicle are deteriorated because a vast separation region, which is called the separation bubble, appears in the boundary layer on the wing at angles of attack corresponding to the standard flight regime of the vehicle. The separation bubble increases the airfoil component of the wing drag and leads 


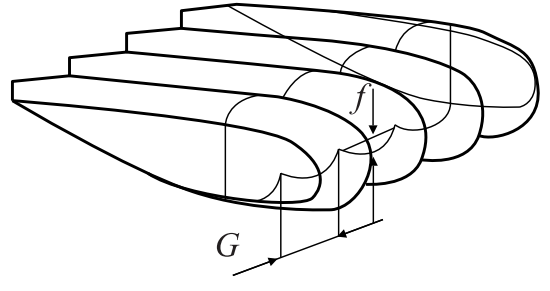

(a)

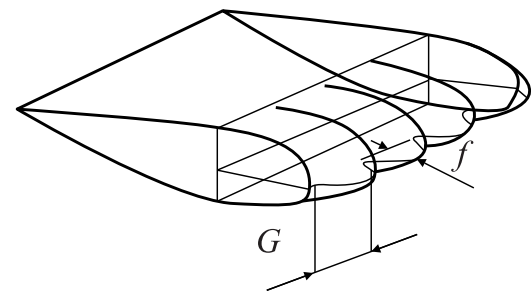

(b)

Figure 1 Wavy wing: (a) research direction 1 - simulation of a parafoil; and (b) research direction 2 - simulation of a whale's fin

to flow stall at a critical angle of attack lower than that at Reynolds numbers above 500,000. Thus, the maximum lift force of the wing decreases. Moreover, the separation bubble enhances the effect of the hysteresis of the aerodynamic characteristics of the wing, which means that the lift force of the wing after reaching the supercritical angle of attack is recovered at a smaller angle of attack than the value at which flow stall occurred. The structure of the boundary layer on a smooth wing at low Reynolds number has been studied in much detail, e. g., in $[2-8]$. There are also available software tools that allow calculating the twodimensional (2D) flow around the airfoil that take into account the boundary layer and Reynolds number effects [9, 10].

It is also known that early turbulization of the boundary layer can alleviate the adverse effect of the separation bubble and increase the critical angle of attack of the wing at low Reynolds numbers. This can be achieved with the use of a tripping wire ahead of the wing [11], surface roughness [12], or vortex generators $[13,14]$. The problem is that the methods proposed in the abovementioned publications either are difficult in implementation or lead to an increase in drag at low angles of attack. Therefore, there is an ongoing search for optimal shapes of vortex generators. Two seemingly similar recent types of investigations can be noted: wavy wing $[15,16]$ and wing with tubercles on the leading edge [17-20].

These wing shapes, however, have different origins; correspondingly, the airfoil modification shapes are also different. The first shape was obtained from the analysis of $[21,22]$; it has the wavy surface parameters illustrated in Fig. $1 a$ and resembles a parafoil as a whole. The second shape originated from simulating a whale's fin (Fig. 1b) [17]. The leading edge is usually shaped as a sine curve with the maximum magnitude $h=2 \%-10 \%$; further along the chord, the profile of this hump merges with the initial airfoil [19].

There is some disagreement in the wing modification notation in [15-20]. In this paper, the following classification is used. A usual wing with no tubercles 
and troughs on the surface is called the classical wing, and a wing with tubercles and troughs is called the wavy wing. The papers [17-20] were aimed at finding advantages of the wavy wing over the classical wing, but the results were contradictory. At Reynolds numbers of 505,000-520,000 and a finite-span wing model simulating the whale's fin, the wavy find was found to be advantageous [18]: a 40 percent increase in the critical angle of attack, a 6 percent increase in the maximum lift force, and a decrease in drag at supercritical angles of attack were observed. Stein and Murray [23] performed the experiments for the angles of attack $0^{\circ}<\alpha<12^{\circ}$ and the Reynolds number of 250,000, using a nominally $2 \mathrm{D}$ wing with sinusoidal waviness of the leading edge, which had averaged waviness parameters (with respect to those on the whale's fin). They found the aerodynamic characteristics of the wavy wing to be worse than those of the classical wing. This deterioration was manifested both as a lower maximum lift force and as a higher drag force. Subsequent studies [24] showed that, indeed, the prestall characteristics of the wavy wing are better than those of the classical wing at $\operatorname{Re}=534,000-631,000$ in tests of the whale's fin model; vice versa, the aerodynamic characteristics of the wavy wing at $R e=274,000-277,000$ in a $2 \mathrm{D}$ flow are worse than those of the smooth wing. Stanway [25] studied a flapping wing of the same shape as that studied in [18] in the range of Reynolds numbers from 44,000 to 120,000. Static measurements (without flapping) showed that the whale's fin model with a wavy leading edge exhibits a decrease in the maximum lift force, except for the case with $\operatorname{Re}=120,000$.

Activities of Johari et al. [19] and Hansen et al. [20] were aimed at studying the influence of the waviness parameters, in particular, the size and amplitude of sinusoidal waviness of the leading edge, on the aerodynamic characteristics of the airfoil. Testing the NACA 63-0021 airfoil at the Reynolds number $\operatorname{Re}=183,000$, Johari et al. found that the best characteristics are provided by the airfoil with the waviness amplitude $f=0.025$ and with the wave length $G=0.25$ (of the chord). The critical angle of attack of the airfoil with such waviness parameters was $4.4^{\circ}$ smaller than that of the classical wing, while the maximum value of the lift force was only $1 \%$ lower than that of the classical airfoil. The goal of [20] was to determine the best relationship between the wave amplitude and length, and also the ratio of the wave amplitude to the boundary layer thickness. The best aerodynamic characteristics of the airfoil were obtained at $f=0.03$ and $G=0.11$.

In previous authors' publications $[15,16]$, the flows around the classical and wavy wings were compared at the Reynolds numbers $R e=120,000-170,000$. The waviness extended over the entire wing along the chord (see Fig. 1a). The ratios of the waviness parameters were $G=0.13$ and $f=0.01$, which are lower than the domain covered in $[19,20]$. It was noted that the critical angle of attack of the wavy wing was greater than that of the classical wing under conditions of lowfree-stream turbulence $(\varepsilon=0.04)$. When the models were placed into another wind tunnel with the turbulence level of $0.7 \%$ for measuring their aerodynamic 
characteristics, this advantage, however, became much less significant and the maximum lift force was approximately identical [15].

To find the reasons for the differences in the aerodynamic characteristics of the same wing model, the low-turbulence wind tunnel was equipped with its own aerodynamic balance, and some tests were performed to study the influence of turbulence on the characteristics of the classical wing at low Reynolds numbers. These tests showed that the change in the turbulence level from $0.04 \%$ to $0.63 \%$ increases the critical angle of attack of the wing from $7^{\circ}$ to $11^{\circ}$ and increases the maximum lift force by $23 \%$ [26]. It was shown [27] that the aerodynamic characteristics of the model can also be substantially affected by the acoustic field of the wind tunnel.

The study performed in this work was aimed at comparing the aerodynamic characteristics of the classical and wavy wings under conditions of a T-324 lowturbulent wind tunnel $(\varepsilon=0.04 \%)$ and also at elucidating the boundary layer structure and evolution of the separated flow at near-critical angles of attack of the classical and wavy wing. The use of an asymmetric airfoil allowed to trace the influence of surface waviness on the boundary layer formed by different pressure distributions over the wing chord.

\section{EXPERIMENTAL TECHNIQUES}

\subsection{Wing Models}

In these experiments, a wing model with the Z 15-25 airfoil was used (Fig. 2). A typical feature of this airfoil is the fact that the maximum deflection of the upper arc is located at $15 \%$ along the chord, while the maximum deflection of the lower arc is located at 25\% (see Fig. 2) along the chord. The study of this airfoil with the XFOIL program showed that its characteristics at the near-stall positive angles of attack are close to the characteristics of a symmetric airfoil with the maximum thickness at $15 \%$ along the chord; at negative

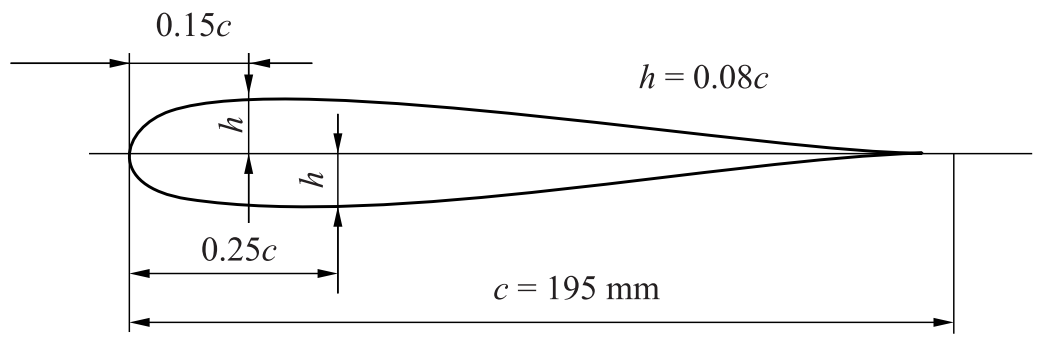

Figure 2 Airfoil 


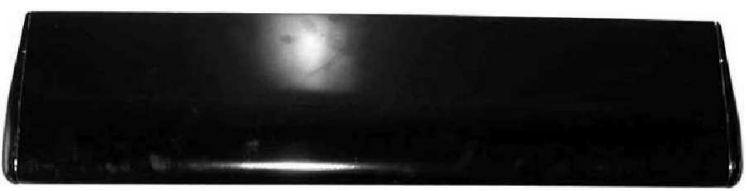

(a)

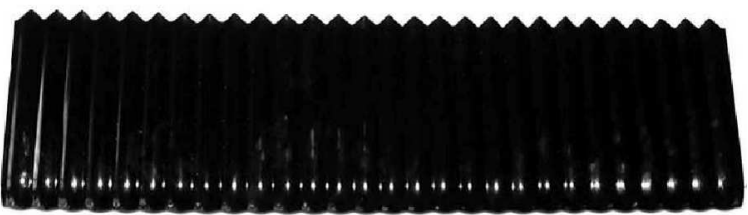

(b)

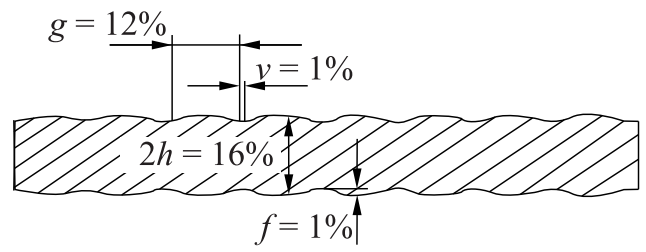

(c)

Figure 3 Geometric parameters of wing models: (a) plan view of the classical wing; (b) plan view of the wavy wing; and (c) cross-sectional view of the wavy wing at $15 \%$ along the chord. Wing chord $c=195 \mathrm{~mm}$; wing span $L=700 \mathrm{~mm}$; and aspect ratio $\lambda=3.5$

angles of attack, its characteristics are close to the characteristics of a symmetric airfoil with the maximum thickness at $25 \%$ along the chord. Thus, the characteristics of this airfoil at near-stall angles of attack illustrate two symmetric airfoils with different locations of the maximum thickness along the chord.

Two models (classical and wavy) with this airfoil shape and with the aspect ratio $\lambda=3.5$ were fabricated. The waviness parameters are shown in Fig. 3 .

\subsection{Oil-Film Visualization}

The oil-film visualization was performed with a mixture of kerosene with addition of oil and luminescent powder. During the experiment, the model was amounted at a necessary angle of attack, the mixture for visualization was applied, and the wind tunnel was actuated. The model was in the flow for $10-15 \mathrm{~min}$. The exposure time was chosen so that the layer of the visualization mixture did not 
trickle down when the flow was switched off. After that, the model was taken out from the wind tunnel and was placed into a dark room. An ultraviolet lamp was switched on, and the luminescent powder remaining on the surface started to glow. The flow visualization pattern on the wing surface was photographed with a Canon EOS 400 digital camera.

\subsection{Infrared Visualization}

Infrared visualization patterns in the boundary layer are the temperature fields along the axis of symmetry of the classical and wavy wings. The study was performed with a TKVr-IFP SVIT IR imager.

The following technique was used to measure the temperature field on the wing surface (Fig. 4):

(1) the wind tunnel was started and operated during a time necessary for flow velocity stabilization;

(2) the objective of the IR camera was closed with a cover, and the wing surface was illuminated with a source of IR radiation, which was a powerful incandescent lamp with a metallic deflector. It should be noted that the IR imager objective should be closed; otherwise, its calibration is upset, and the accuracy of temperature measurements becomes lower; and

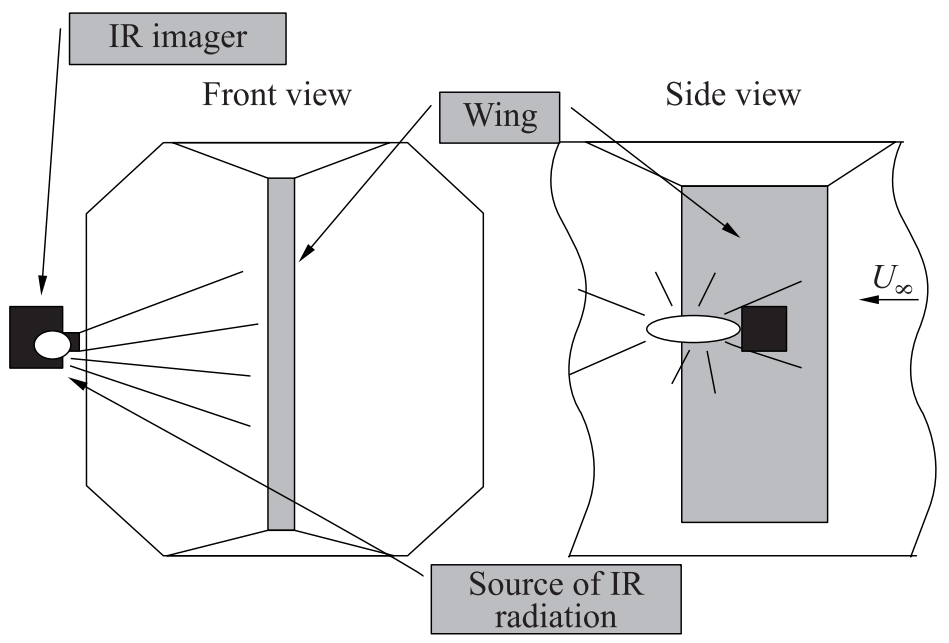

Figure 4 Scheme of IR measurements 
(3) after an exposure time of 1-2 min, the lamp was switched off, the IR imager objective was opened, and a sequence of IR images was recorded with a frequency of $25 \mathrm{~Hz}$ and duration of 2-5 min. Each measurement includes the domain captured by the objective and divided into $130 \times 130$ cells, which corresponds to the number of pixels of the photosensitive matrix of the IR imager. The IR imager allows obtaining the temperature field of a chosen area or dependences of temperature on the streamwise or spanwise coordinate in a certain section.

Thus, each flow regime contains a set of thermograms. A thermogram with the surface temperature varying from 20 to $24{ }^{\circ} \mathrm{C}$ within $\pm 0.2{ }^{\circ} \mathrm{C}$ was chosen from this set. Thus, the blue color in all thermograms presented below corresponds to the lower limit of the model surface temperature $\left(20 \pm 0.2{ }^{\circ} \mathrm{C}\right)$, and the red color refers to the upper limit $\left(24 \pm 0.2^{\circ} \mathrm{C}\right)$. Infrared visualization supplements the oil-film visualization results and also allows flow visualization on the windward side of the wing, where the use of oil-film visualization is problematic. The method of flow visualization with an IR imager was previously tested in [28].

\subsection{Balance Measurements}

In addition to visualization, the aerodynamic characteristics of these wings were measured by a balance [29]. The error of measurements was smaller than $1.5 \%$ of the measured value for the lift force and smaller than $2 \%$ of the measured value for the drag force.

\section{EXPERIMENTAL RESULTS}

The results of aerodynamic characteristics measurements in Fig. 5 are present. As the flow pattern is symmetric with respect to the axis of symmetry of the wing, Figs. 6-15 show the results of visualization (left column) and its interpretation (right column). Different schemes are used for IR visualization: the wing aligned at an appropriate angle to the free stream is shown, with thermographs of some part of the leeward and windward sides of the wing are given above and below.

Let first consider the structure of the boundary layer in the case with the maximum airfoil thickness at $15 \%$ along the chord. This corresponds to positive angles of attack of these wing models. At the angle of attack equal to $5^{\circ}$, an attached flow is observed both for the classical wing and for the wavy wing, with formation of a vast separation bubble on the classical wing (see Fig. 6a) and local bubbles along the lines of the troughs on the wavy wing (see Fig. 6b). 


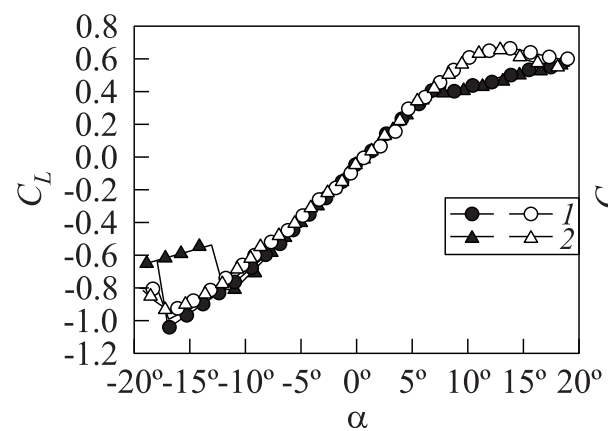

(a)

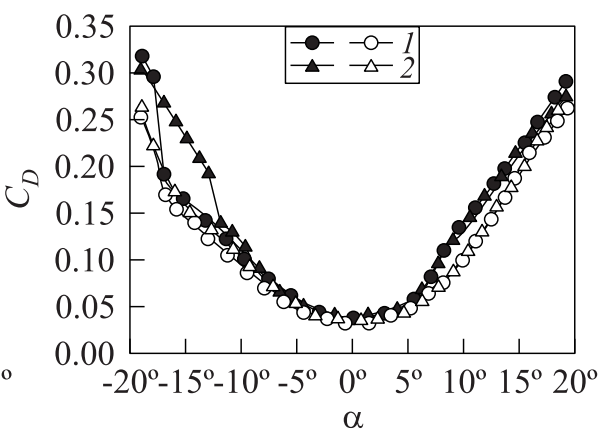

(b)

Figure 5 Dependence of the lift $(a)$ and the drag $(b)$ coefficients on the angle of attack ( 1 - increasing and 2 - decreasing). Filled signs refer to classical wings and black to wavy wings

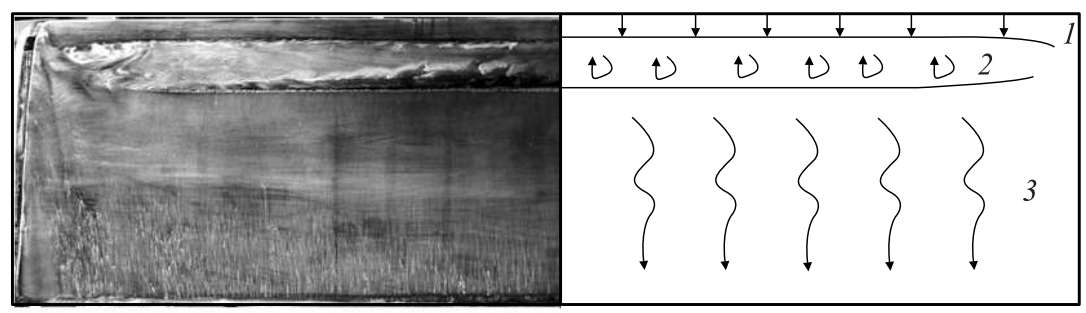

(a)

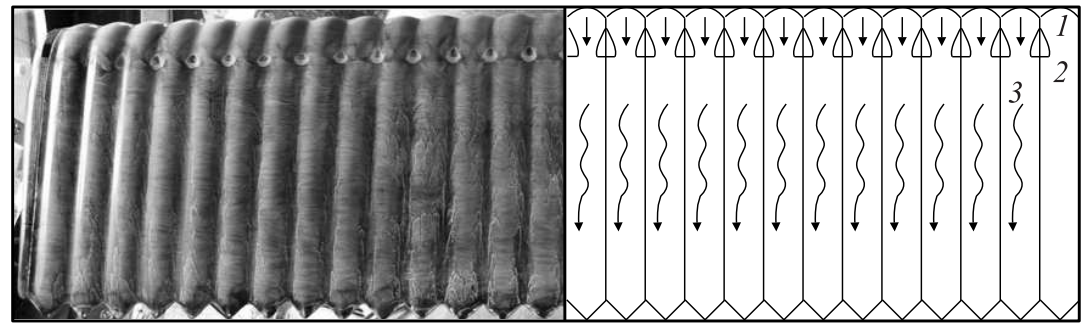

(b)

Figure 6 Oil-film visualization on the leeward side of the classical $(a)$ and wavy $(b)$ wings and its interpretation; angle of attack $\alpha=5^{\circ}\left(C_{L}=0.30 ; C_{D}=0.05\right): 1-$ laminar boundary layer; 2 - separation bubble; and 3 - turbulent boundary layer 

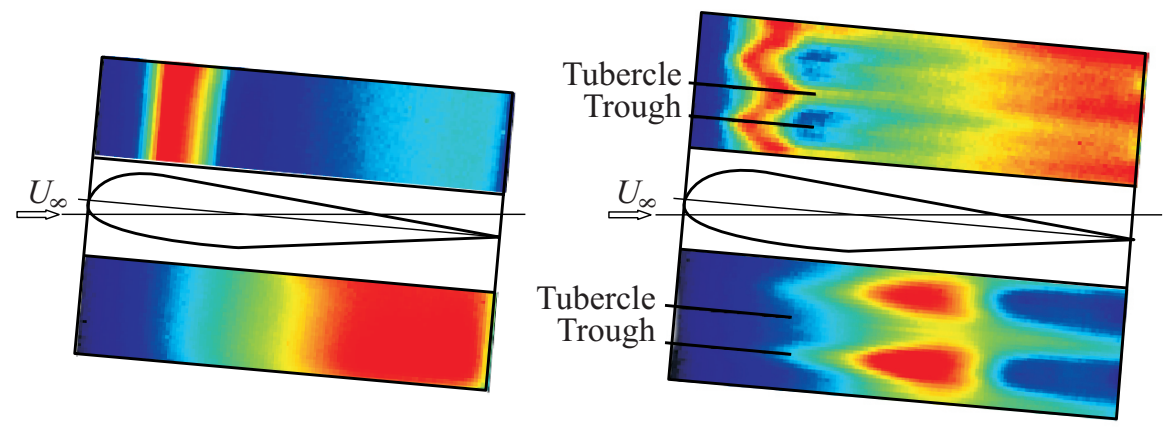

(a)
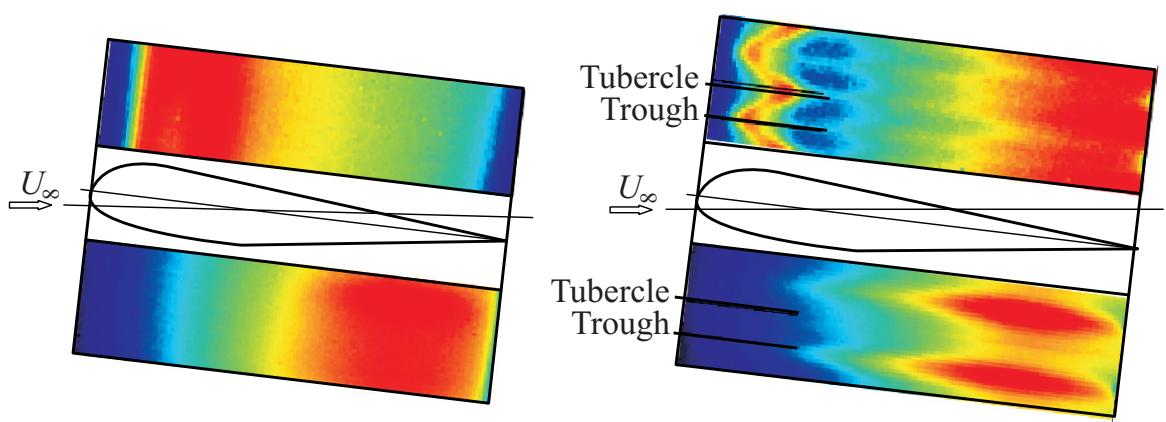

(b)

Figure 7 Infrared visualization on the classical (left column) and wavy (right column) wings at the angles of attack $\alpha=5^{\circ}(a)$ and $10^{\circ}(b)$.

Infrared visualization on the classical wing (see Fig. $7 a$, left column) confirms the formation of a separation bubble on the leeward side of the wing and a laminar flow without separation on the windward side. For the wavy wing (see Fig. $7 a$, right column), separation bubbles are formed both on the windward and leeward sides of the wing.

Already at the angle of attack equal to $8^{\circ}$, however, flow stall from the leading edge occurs on the classical wing. This is manifested as termination of increase in the drag force. Oil-film visualization demonstrates the presence of a vast separation region (see Fig. 8).

In the IR visualization patterns (see Fig. 7b, left column), flow stall is seen as a smoother decrease in temperature downstream from the separation line, because heat transfer in the separation region is less intense than in the boundary layer of the attached flow. 


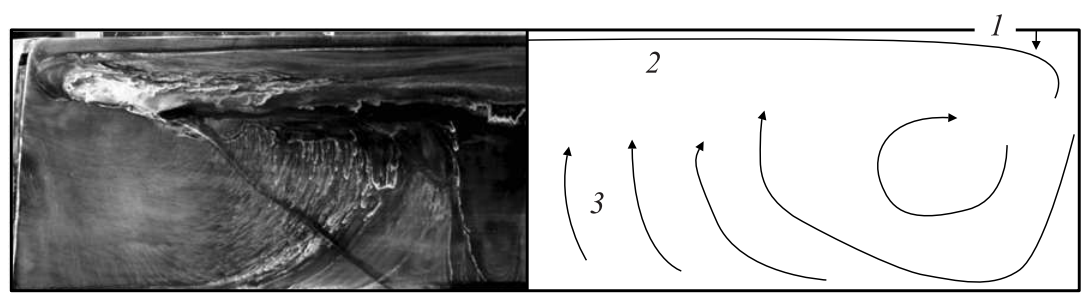

Figure 8 Oil-film visualization on the leeward side of the classical wing and its interpretation; angle of attack $\alpha=8^{\circ}\left(C_{L}=0.40 ; C_{D}=0.12\right): 1$ - laminar boundary layer; 2 - stagnant region; and 3 - reverse flow

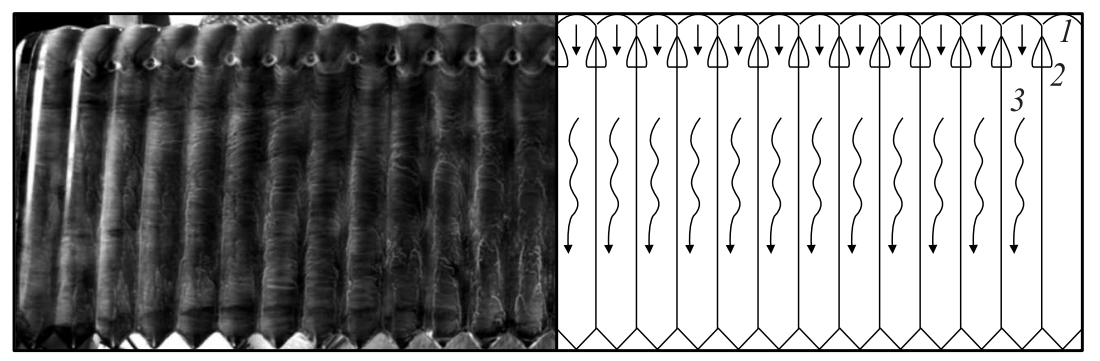

Figure 9 Oil-film visualization on the leeward side of the wavy wing and its interpretation; angle of attack $\alpha=13^{\circ}\left(C_{L}=0.68 ; C_{D}=0.15\right): 1$ - laminar boundary layer; 2 - separation bubbles; and 3 - turbulent boundary layer

As is seen from the oil-film visualization pattern, the attached flow regime persists on the wavy wing up to the angle of attack of $13^{\circ}$ (see Fig. 9). The lift coefficient for the wavy wing reaches 0.68 , which is 1.55 times higher than that for the classical wing. Infrared visualization allows to conclude that the laminar-turbulent transition on the leeward side of the wing occurs at $10 \%-25 \%$ along the chord, both along the line of troughs and along the line of tubercles; after that, the growth of a turbulent boundary layer with minor nonuniformities in the spanwise direction is observed (see Fig. $7 b$, right column). A region with an increased thickness of the boundary layer along the line of troughs is identified on the windward side of the wing at the angle of attack equal to $10^{\circ}$. It is not possible to argue definitely whether there are exist separation bubbles or not, because a decrease in temperature typical for separation bubbles is not observed behind these regions.

Flow stall on the wavy wing progresses more slowly than on the classical wing. It is seen from oil-film visualization results that the boundary layer separation and reverse flow are observed in the central part of the wing, while the boundary layer at the wingspan tip remains attached (see Fig. 10). 


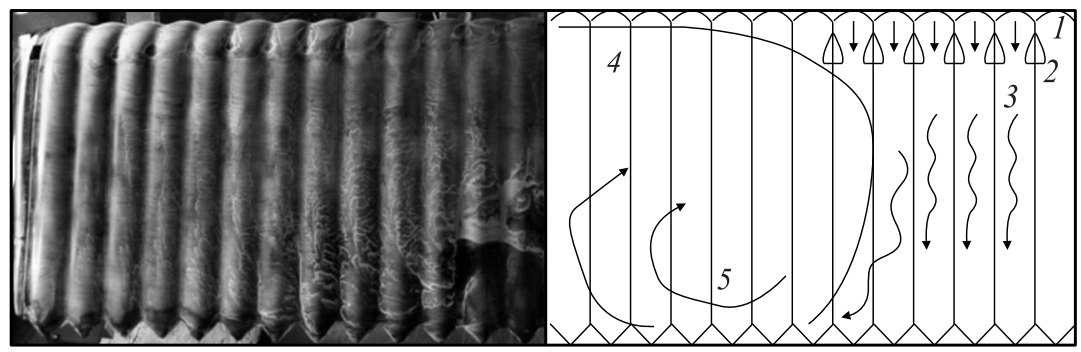

Figure 10 Oil-film visualization on the leeward side of the wavy wing and its interpretation; angle of attack $\alpha=15^{\circ}\left(C_{L}=0.61 ; C_{D}=0.2\right): 1$ - laminar boundary layer; 2 - separation bubbles; 3 - turbulent boundary layer; 4 - stagnant region; and 5 - reverse flow

The case with the maximum wing thickness at $25 \%$ along the chord corresponds to negative angles of attack. At the angle of attack equal to $-5^{\circ}$, an attached flow with formation of separation bubbles in accordance with the same scenario as in the case with the maximum thickness at $15 \%$ along the chord is observed both on the classical and wavy wings. Infrared visualization, however, allows some specific features for the wavy wing to be identified (see Fig. 11a).

At the angle of attack $\alpha=-5^{\circ}$, the separation bubbles on the windward side are smaller and are located further upstream than in the case with $\alpha=-5^{\circ}$, and the turbulent flow region behind these separation bubbles is also smaller. Along the tubercles, apparently, the boundary layer has a laminar structure and a greater thickness, which forms an increased temperature region, as compared to the trough area. The laminar boundary layer along the tubercle line on the windward side is also more extended. The temperature peak along the tubercle is located at $20 \%$ along the chord at $\alpha=5^{\circ}$ (see Fig. $7 a$, right column) and at $50 \%$ along the chord at $\alpha=-5^{\circ}$ (see Fig. 11a, right column).

At the angle of attack $\alpha=-10^{\circ}$, the attached flow regime is observed both on the classical and wavy wings (see Fig. 11b). Among specific features, a delay of the laminar-turbulent transition on the wavy wing along the tubercle line can be noted.

The transition along the line of troughs is characterized by a drastic decrease in surface temperature behind the separation bubble (blue area along the line of troughs). This fact agrees with the results of oil-film visualization. There is no separation of the flow along the line of tubercles, as is seen from the oil-film patterns; thus, the local red area along the tubercle in the case considered can testify to the presence of a thick laminar boundary layer. The boundary layer becomes turbulized downstream of the point at $50 \%$ along the chord, and the surface temperature decreases. Beginning from $60 \%$ along the chord, however, it 

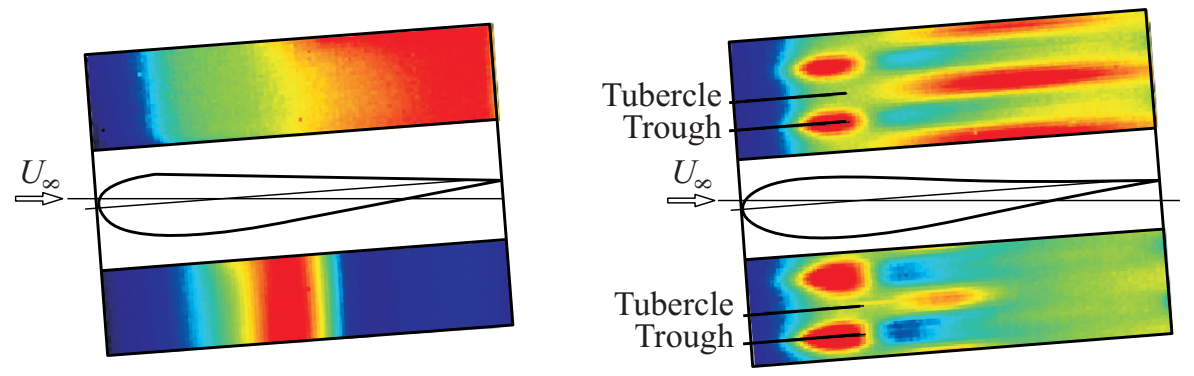

(a)
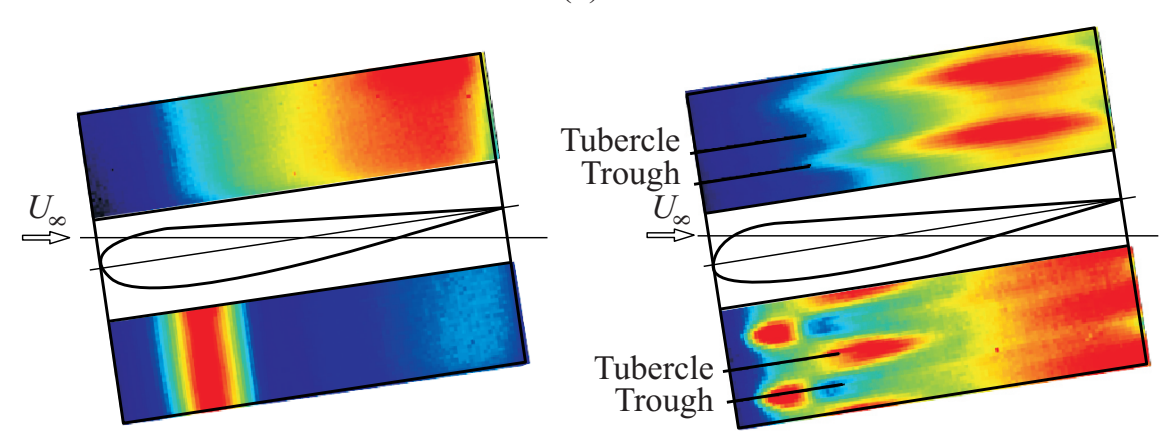

(b)

Figure 11 Infrared visualization on the classical (left column) and wavy (right column) wings at the angles of attack $\alpha=-5^{\circ}(a)$ and $-10^{\circ}(b)$.

increases again, owing to the increase in thickness of the boundary layer, which is now turbulent.

The attached flow on the classical wing persists in this case up to the angle of attack of $-17^{\circ}$. The separation bubble is also observed, and the front and rear boundaries of the separation bubble are obviously curved in accordance with local angles of attack for the finite-span wing (see Fig. 12).

The maximum lift coefficient reaches 1.03 at the angle of attack equal to $17^{\circ}$, followed by flow stall from the leading edge. Oil-film visualization shows that the flow structure changes from the attached flow to the stall flow, with formation of a vase reverse flow region (see Fig. 13). As the angle of attack is reduced, the stall flow regime is observed to the angle of $12^{\circ}$; in this case, the drag force is only $10 \%$ lower than the value at the angle of attack equal to $18^{\circ}$, and the lift coefficient stays around $C_{y}=-0.6$, which is also typical for flow stall. Thus, there is a vast area of the hysteresis of the aerodynamic characteristics for the 


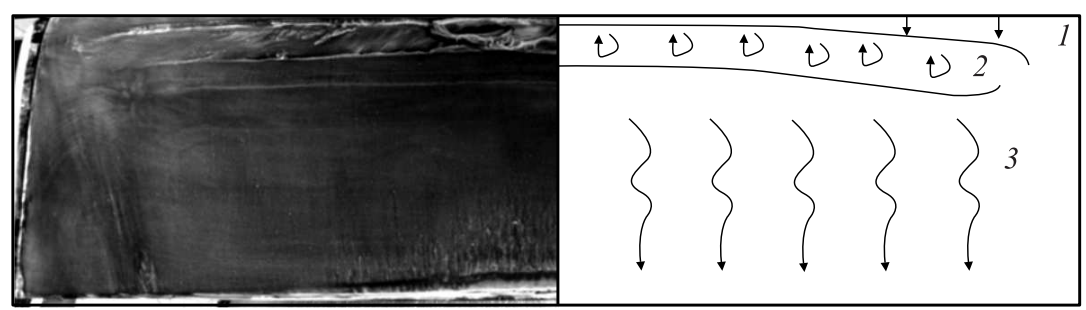

Figure 12 Oil-film visualization on the leeward side of the wavy wing and its interpretation; angle of attack $\alpha=-14^{\circ}\left(C_{L}=-0.93 ; C_{D}=0.15\right): 1-$ laminar boundary layer; 2 - separation bubbles; and 3 - turbulent boundary layer

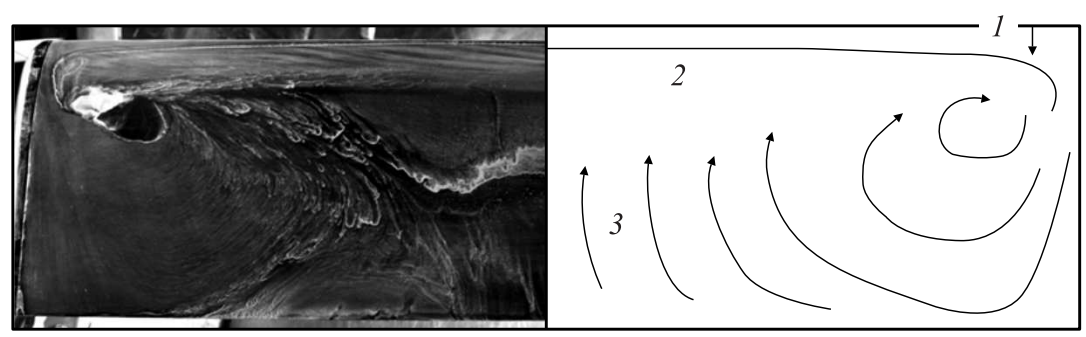

Figure 13 Oil-film visualization on the leeward side of the wavy wing and its interpretation; angle of attack $\alpha=-14^{\circ}$, reduction of the angle of attack $\left(C_{L}=-0.56\right.$; $\left.C_{D}=0.21\right): 1$ - laminar boundary layer; 2 - stagnant region; and 3 - reverse flow

classical wing. This fact is illustrated by two visualization patterns obtained at the angle of attack equal to $14^{\circ}$ in the subcritical (see Fig. 12) and supercritical (see Fig. 13) flow regimes.

For the wavy wing, the lift coefficient $C_{L}$ decreases as the angle of attack of $17^{\circ}$ is reached. The domain of separation bubbles in this case is smaller than that for the classical wing (see Fig. 14), and the maximum lift coefficient of the wing is the same as for the classical wing. Flow stall on the wavy wing occurs more slowly than on the smooth wing. Gradual development of boundary separation is observed, beginning from the wing center (see Fig. 15). Another specific feature of flow stall on the wavy wing is intermittency of the flow on the interface between the separated and attached flow regions, which is manifested in the emergence of model vibrations. A detailed study of this phenomenon requires additional investigations. The averaged values of the aerodynamic coefficients show that there is no hysteresis of the aerodynamic characteristics of the wavy wing. The decrease in the lift force after its peak value is less pronounced than on the classical wing. 


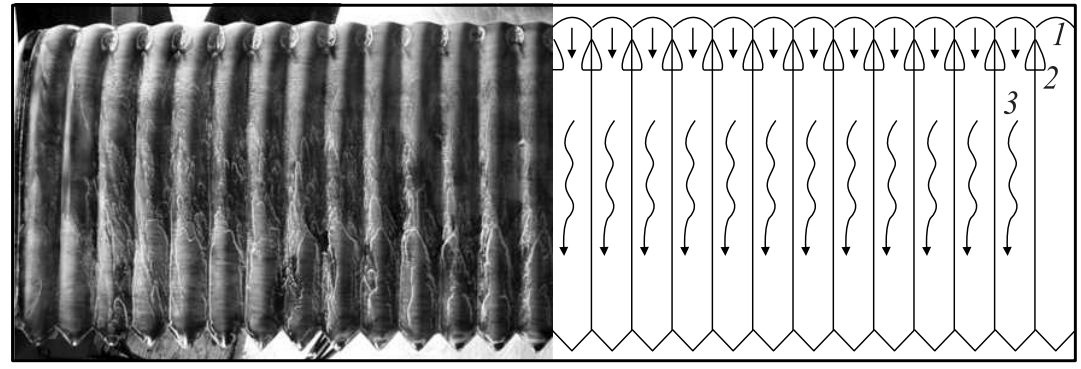

Figure 14 Oil-film visualization on the leeward side of the wavy wing and its interpretation; angle of attack $\alpha=-14^{\circ}\left(C_{L}=-1.00 ; C_{D}=0.14\right): 1$ laminar boundary layer; 2 - separation bubbles; and 3 - turbulent boundary layer

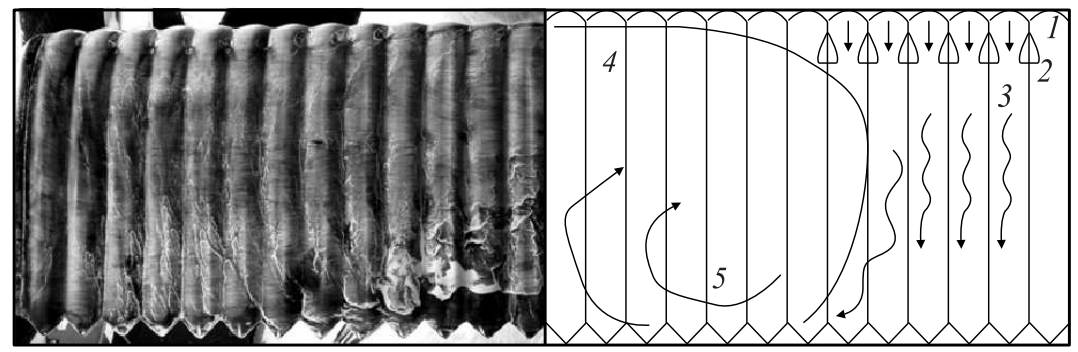

Figure 15 Oil-film visualization on the leeward side of the wavy wing and its interpretation; angle of attack $\alpha=-18^{\circ}\left(C_{L}=-0.8 ; C_{D}=0.22\right): 1-$ laminar boundary layer; 2 - separation bubbles; 3 - turbulent boundary layer; 4 - stagnation region; and 5 - reverse flow

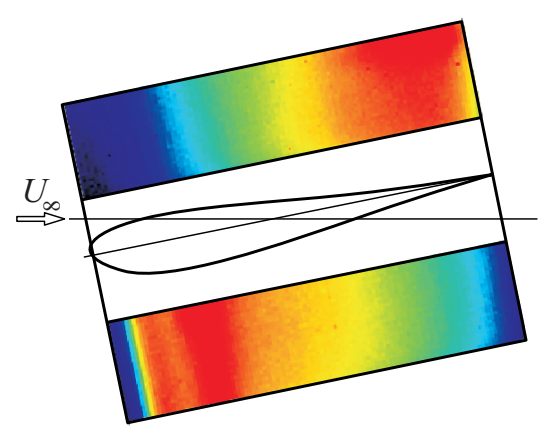

(a)

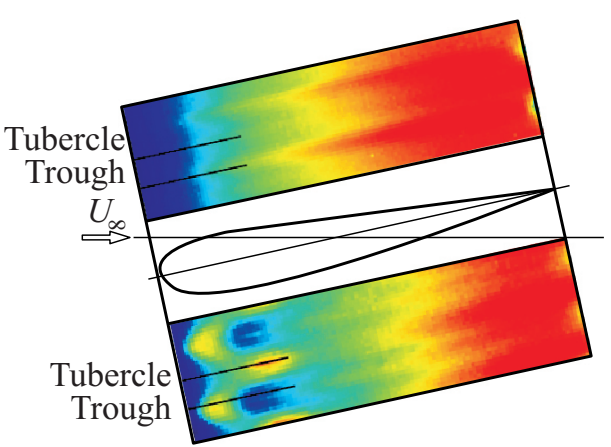

(b)

Figure 16 Infrared visualization on the classical wing in the supercritical flow regime $(a)$ and on the wavy wing $(b)$ at the angle of attack $\alpha=-15^{\circ}$. 
The results of IR visualization (Fig. 16) on the classical wing confirm the fact of a separated flow on the leeward side of the wing and an attached laminar flow on the windward side. The temperature distribution over the wing span is uniform. For the wavy wing, the temperature distribution over the wing space on the windward side is not uniform, but one cannot argue whether it is associated with local separation or with a greater thickness of the attached boundary layer in the trough, because no laminar-turbulent transition region with a clearly expressed decrease in temperature is observed.

\section{CONCLUDING REMARKS}

A comprehensive study of the flow around the wing of a small-scale flying vehicle with the aspect ratio $\lambda=3.5$ is performed. The aerodynamic characteristics of the classical wing and of the wing with a wavy surface are obtained for Reynolds number ranging from 1.2 to $1.4 \cdot 10^{5}$ typical for this class of flying vehicles. In addition, the surface flow patterns at some characteristic angles of attack are obtained by the method of oil-film visualization.

The measured results confirm the adverse effect of a large separation bubble on the classical wing on its aerodynamic characteristics. For the classical wing, the shift of the maximum airfoil thickness downstream from $15 \%$ to $25 \%$ leads to a 1.5-fold increase in the critical angle of attack, but a vast region of the hysteresis of the aerodynamic characteristics appear in this case.

The proposed method of wing modification by making the wing surface wavy allows significant improvement of the aerodynamic characteristics of the wings of small-scale flying vehicles. For airfoils with the maximum thickness at $15 \%$ along the chord, surface waviness allows the critical angle of attack and the maximum lift force to be increased by a factor of 1.7 and 1.55 , respectively. For airfoils with the maximum thickness at $25 \%$ along the chord, the increase in the critical angle of attack is insignificant, and the maximum lift force remains at the same level. In this case, however, surface waviness eliminates the hysteresis of the aerodynamic characteristics. Flow stall from the leading edge on the wavy wing is smoother than on the classical wing, and flow intermittency between the separated and attached regimes is observed on some part of the wing surface, which leads to characteristic vibrations of the wing. These vibrations can serve as a signal of approaching critical flow regimes for automatic control systems of the flying vehicle.

A comparison of the results of this work with the data of $[19,20]$ confirms that the waviness parameters for wings operating at Reynolds numbers below $\operatorname{Re}<200,000$ should be $G<0.15 c$ and $f<0.015 c$ (see Fig. 3); in this case, both the maximum critical angles of attack and the maximum lift force are greater than the corresponding values for the classical wing. 
Infrared visualization shows that separation bubbles on the windward side of the wavy wing persist up to $5^{\circ}-10^{\circ}$ and lead to turbulization of the boundary layer on some part of the windward side of the wing, whereas a spanwiseuniform laminar boundary layer is observed on the classical wing in these flow regimes. On the other hand, the separation babbles on windward side of wavy wing does not increase the wavy wing drag coefficient at the angle of attack about $5^{\circ}$ as compared with classical wing. So, the numbers of small separation bubbles on wavy wing add less drag than large separation bubble on classical wing.

Further activities in this aspect would involve optimization of wing waviness parameters. The goal of this optimization is, on the one hand, to retain the useful effects, such as the increase in the critical angle of attack and the maximum lift force, and, on the other hand, to reduce the drag force of the wavy wing in the range of subcritical angles of attack to a level lower than that on the classical wing.

\section{ACKNOWLEDGMENTS}

This work was supported by the Grant No. RNP 2.1.2.541 of the Ministry of Education and Science of the Russian Federation and by the State Contract No. GK 14.740.11.0354.

\section{REFERENCES}

1. Pelletier, A., and T. J. Mueller. 1999. Aerodynamic force/moment measurement at very low Reynolds. 46th Annual Conference of the Canadian Aeronautics and Space Institute Proceedings. 59-68.

2. Ward, J. W. 1963. The behavior and effects of laminar separation bubbles on aerofoils in incompressible flow. J. R. Aeronaut. Soc. 67:783-90.

3. Horton, H.P. 1968. Laminar separation bubbles in two- and three-dimensional incompressible flow. Ph.D. Thesis. University of London.

4. O'Meara, M. M., and T. J. Mueller. 1987. Laminar separation bubble characteristics on an airfoil at low Reynolds numbers. AIAA J. 25(8):1033-41.

5. Brendel, M., and T. J. Mueller. 1988. Boundary layer measurements on an airfoil at low Reynolds numbers. AIAA J. Aircraft 25(7):612-17.

6. Fitzgerald, E. J., and T. J. Mueller. 1990. Measurements in a separation bubble on an airfoil using laser velocimetry. AIAA J. 28(4):584-92.

7. Dikovskaya, N. D., and B. Yu. Zanin. 2000. Flow stability investigation upon windward and leeward wing surface. Thermophys. Aeromech. 7(2):201-8. 
8. Boiko, A. V., G. R. Grek, A. V. Dovgal, and V. V. Kozlov. 2006. Phisical mechanism of transition to turbulence in open flows. Moscow-Igevsk: Institute of Computer Investigation. [In Russian.]

9. Drela, M., and M. B. Giles. 1987. Viscous-inviscid analysis of transonic and low Reynolds number airfoils. AIAA J. 25(10):1347-55.

10. Drela, M. 1989. XFOIL: An analysis and design system for low Reynolds number airfoils. Conference on Low Reynolds Number Airfoil Aerodynamics. University of Notre Dame.

11. Schmitz, F. W. 1952. Aerodynamik des flugmodells. Duisburg: Carl Lange Verlag.

12. McMaster, J.H., and M. L. Henderson. 1980. Lowspeed single element airfoil synthesis. Techn. Soaring 2(2):1-21.

13. Lin, J. C. 2002. Review of research on low-profile vortex generators to control boundary-layer separation. Prog. Aerospace Sci. 38:389-420.

14. Gad-el-Hak, M. 2006. Flow control: Passive, active, and reactive flow management. Cambridge University Press.

15. Zverkov, I. D., and B. Yu. Zanin. 2003. Wing form effect on flow separation. Thermophys. Aeromech. 10(2):197-204.

16. Zverkov, I. D., B. Yu. Zanin, and V. V. Kozlov. 2008. Disturbances growth in boundary layers on classical and wavy surface wing. AIAA J. 46(12):3149-58.

17. Watts, P., and F.E. Fish. 2001. The influence of passive, leading edge tubercles on wing performance. 12th Symposium (International) on Unmanned Untethered Submersible Technology Procceedings. Autonomous Undersea Systems Inst.

18. Miklosovic, D. S., M. M. Murray, L.E. Howle, and F. E. Fish. 2004. Leading-edge tubercles delay stall on humpbuck whale (Megaptera novaeangliae) flippers. Phys. Fluids 16(5):39-42.

19. Johari, H., C. Henoch, D. Custodio, and A. Levshin. 2007. Effects of leading-edge protuberances on airfoil performance. AIAA J. 45(11):2634-41.

20. Hansen, K. L., R. M. Kelso, and B.B. Dally. 2011. Performance variations of leading-edge tubercles for distinct airfoil profiles. AIAA J. 46(1):185-94.

21. Zanin, B. U., V. V. Kozlov, and O. V. Mavrin. 1997. About the ways of the global stalling control. Thermophys. Aeromech. 4(4):381-85.

22. Babinsky, H. 1999. The aerodynamic performance of paragliders. Aeronautical J. 103(1027):421-28.

23. Stein, B., and M. M. Murray. 2005. Stall mechanism analysis of humpbuck whale flipper models. Unmanned Untethered Submersible Technology (UUST). Autonomous Undersea Systems Institute.

24. Miklosovic, D. S., and M. M. Murray. 2007. Experimental evaluation of sinusoidal leading edges. J. Aircraft 44(4):1404-7.

25. Stanway, M. J. 2008. Hydrodynamic effects of leading-edge tubercles on control surfaces and in flapping foil propulsion. Master's Thesis. MIT.

26. Zverkov, I. D., V. V. Kozlov, and A. V. Krukov. 2011. Influence of wind tunnel freestream turbulence level on boundary layer separation. Thermophys. Aeromech. 18(2):213-24. 
27. Grundy, T. M., G. P. Keefe, and M. V. Lowson. 2001. Effects of disturbances on low Re aerofoil flows. In: Fixed and flapping wing aerodynamics for micro air vehicle applications Ed. Th. J. Mueller. Progress in astronautics and aeronautics ser. 195.

28. Zverkov, I. D., V. V. Kozlov, and A. V. Krukov. 2010. Investigation of the boundary layer separation on classical and "wavy" wings by thermovision. Newsletter NSU 5(3):20-28. [In Russian.]

29. Kozlov, V. V., I. D. Zverkov, B. U. Zanin, and A. V. Krukov. 2009. A new approach to suppression of the flow instability on MAV wings. 3rd European Conference for Aero-Space Sciences Proceedings. 